\title{
Fictive capital and productivity of labor: technological backwardness through the monetary relations
}

\author{
Daria Dinetc ${ }^{1 *}$ \\ ${ }^{1}$ Irkutsk state transport university, Ulitsa Chernyshevskogo 15, Irkutsk, 664074, Russia
}

\begin{abstract}
The article is devoted to describing system relations of technological stagnation, technical development, labor productivity and monetary standard. It has been shown that world dependence of dollar had based on need to mask labor productivity reduction without inflation methods. It was proven a destruct influence of American economy and its financial structure to quality development of advanced science and technology on a global scale by the comprising analysis of output, number of employers, labor productivity and real investments dynamics on American high-technology industries.
\end{abstract}

\section{Introduction}

A lot of science researches, exposing a damage of financial capital in its virtual and fictive forms, are emphasize to the harmful of financialization, which has been recognized by Keynes, who tall that it was hard to wait a good results of economics if the industry became a by-product of casino games [1]. It means the financialization leads to impossibility of industry production growth because all strategic goals are set in financial sphere to extract resources from producing.

\section{Methods}

The research was based on statistical data processing approaches, comparative and system analysis, describe and predict analytics. The relevant systematic relates were revealed by the combination of theoretical materials and empirical data about the structure of high-tech output and its financing. Describing part of the research was based on induction, deduction, analysis and synthesis methods.

\section{Results}

All the capital goods could redistribute a profit to financial markets on capital regeneration process if the main purpose is increasing of powerful, speed, load capacity, even strength,

\footnotetext{
${ }^{*}$ Corresponding author: dinets_d_a@mail.ru
} 
etc. There are two reasons of this problem:

1.Replacing manual labor with machine without the possibility of subsequent involvement of the released workers in new technological processes with higher labor productivity and the growth of technological rate of replacement labor with capital.

2. The broad money creation mechanism of bank credit and deposit operations.

The relationship between these mechanisms is explained below. First of all we should note, that for a long time a progress of technics has been ahead a progress in technology. A huge capital costs are spent for insignificant changes in data transfer rate, image clarity, uptime, power or equipment accuracy, etc. Nano-world is gradually changing a Microworld, so sometimes even the smallest results mean something, besides the capital costs recover by decrease of labor in producing. But the technology is the same, so it's no creation of new high-producing processes. That's why a labor should simplify their work; reduce the claims for wages and, accordingly, the level of consumption. In the same the prices of innovations increase, so the rate of replacing a labor with machine is increasing more than its power, especially if capital cost was financed with borrows.

The result of constant struggle for the powerful of techniques is growth of funds producing compared the producing of customer goods. It leads to decrease of labor productivity in natural units. Decreasing of labor productivity, accordingly, leads to decreasing of value added, which is the main source of profit [2]. But we know that profit should be distributed on financial markets. In response to slower of labor productivity firms try to increase a productivity of machines. It leads to creation of spiral, which twists with the growth of marginal costs of technics.

New technics should be recovered during the standard business cycle at the current price level of the product produced by the industry. Otherwise the fictive capital can "enslave" fixed capital. That process is much more possible if more borrows were attracted for financing the capital costs. It means the equipment remains the same but for its recovering and debt repayment the prices on consumer markets should be raised. It's a constantly renewable process when new technical characteristics of equipment are not requested by consumers. If the demand to some consumer good is not satisfied due to existing equipment, than capital costs would led to economic growth. But if the strategic goal is just productivity of machines, it leads to credit expansion, financial bubbles etc.

Labor productivity level changes because of capital productivity and capital-labor ratio. We suppose that if the main source of labor productivity growth is capital-labor ratio, it could mean the prices were raised. If that situation is not about just one firm, but an industry or some strategic firms, than capital would be loosed for technological development.

A very important indicator of productivity is multifactor productivity. It correlates a share of each resource in producing and the real output. A positive multifactor productivity means combine of resources is effective; accordingly, a negative meaning is a sign of inefficiency and losing of value.

It's significant that multifactor productivity in some key industries of American economy has been decreased for years (according the United States department of labor data - table 1).

Table 1. The growth rate of multi-factor productivity in some sectors of American industry [3]

\begin{tabular}{|c|c|c|}
\hline \multirow{2}{*}{ Industry } & \multicolumn{2}{|c|}{ Period } \\
\cline { 2 - 3 } & $1992-2004$ & $2004-2016$ \\
\hline Animal food & 1.3 & -1.6 \\
\hline Beverages & 1.0 & -0.4 \\
\hline Tobacco & 0.6 & -2.2 \\
\hline Fabric mills & 1.5 & -0.9 \\
\hline Textile and fabric finishing mills & 0.5 & -0.5 \\
\hline
\end{tabular}




\begin{tabular}{|c|c|c|}
\hline Sawmills and wood preservation & 0 & 1.7 \\
\hline Plywood and engineered wood products & -1.1 & 0.6 \\
\hline Petroleum and coal products & 1.6 & -1.9 \\
\hline Basic chemicals & 0.8 & 0 \\
\hline Agriculturachemicals & 1.8 & -1.4 \\
\hline Pharmaceuticals and medicines & -1.3 & -3.2 \\
\hline Plastics products & 0.9 & -0.1 \\
\hline Rubber products & 1.4 & -0.3 \\
\hline Iron and steel mills and ferroalloys & 1.8 & 1.5 \\
\hline Boilers, tanks, and shipping containers & 0.7 & -0.8 \\
\hline Hardware & 0 & -1.3 \\
\hline Industrial machinery & 1.2 & -0.3 \\
\hline Computer and peripheral equipment & 20.2 & 6.1 \\
\hline Semiconductors and electronic components & 17.8 & 1.3 \\
\hline Motor vehicles & 0.5 & 0 \\
\hline Aerospace products and parts & -0.6 & 0.9 \\
\hline Railroad rolling stock & 1.5 & -1 \\
\hline Total manufacturing & 2 & -0.3 \\
\hline
\end{tabular}

The positive cumulated effect is accompanying only the branches of information technologies and non-mining export. Probably it is not a result of digital revolution, but just a consequence of prices growth and inflation distribution of value.

Observe of the labor statistics in main export industries of US confirms our opinion (Fig.1-5).

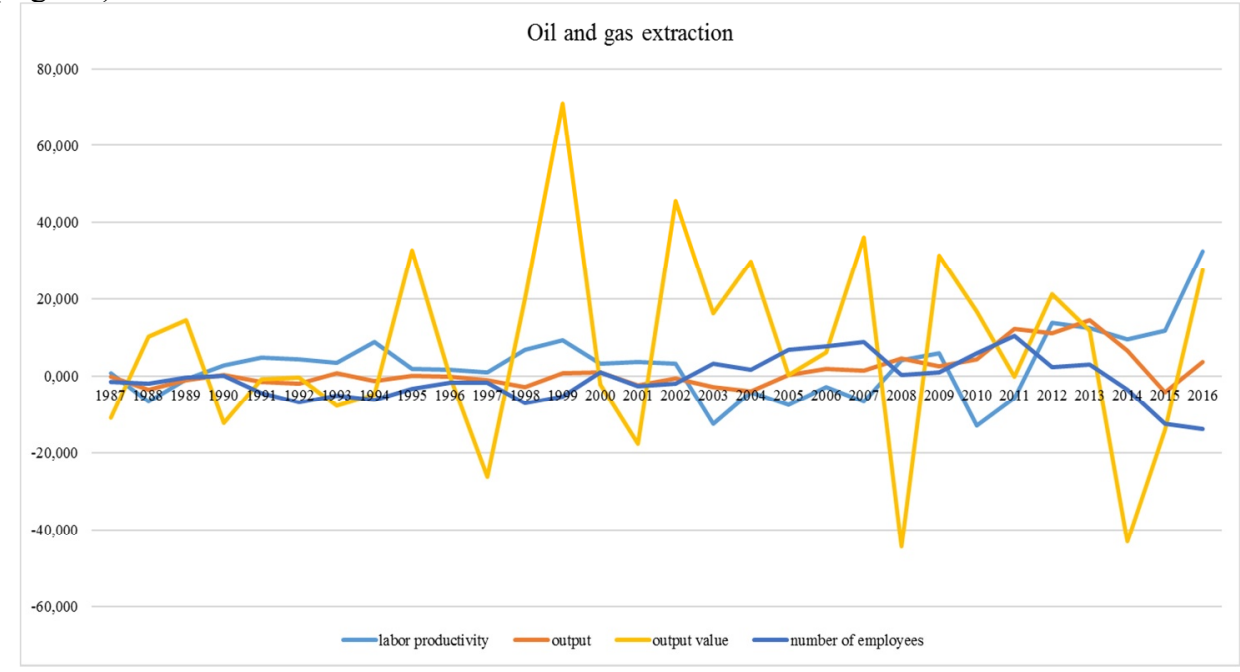

Fig. 1. Growth in mining [4] 


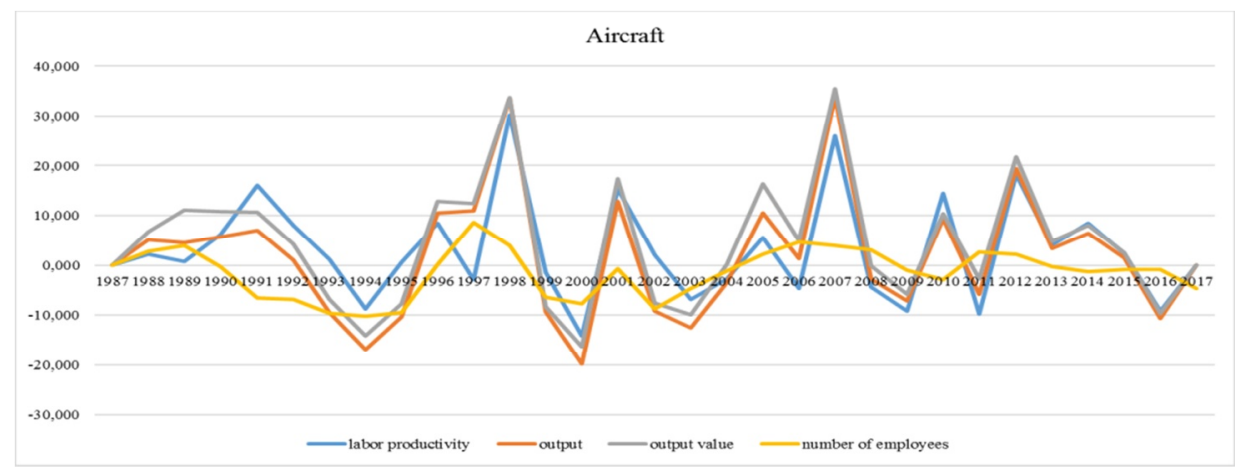

Fig. 2. Growth in aircraft manufacture [4]

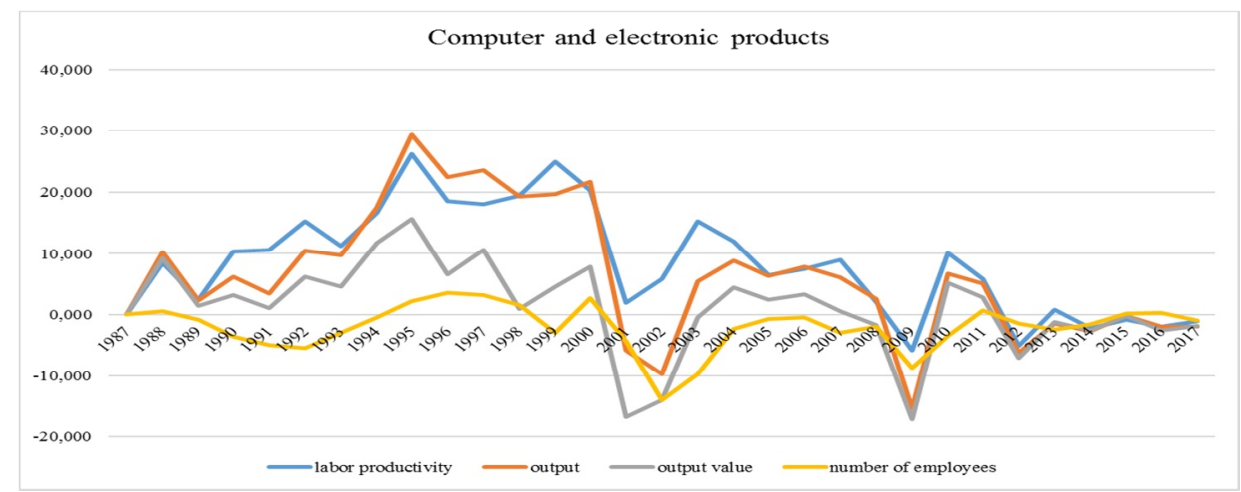

Fig. 3. Growth in computer and electronic manufacture [4]

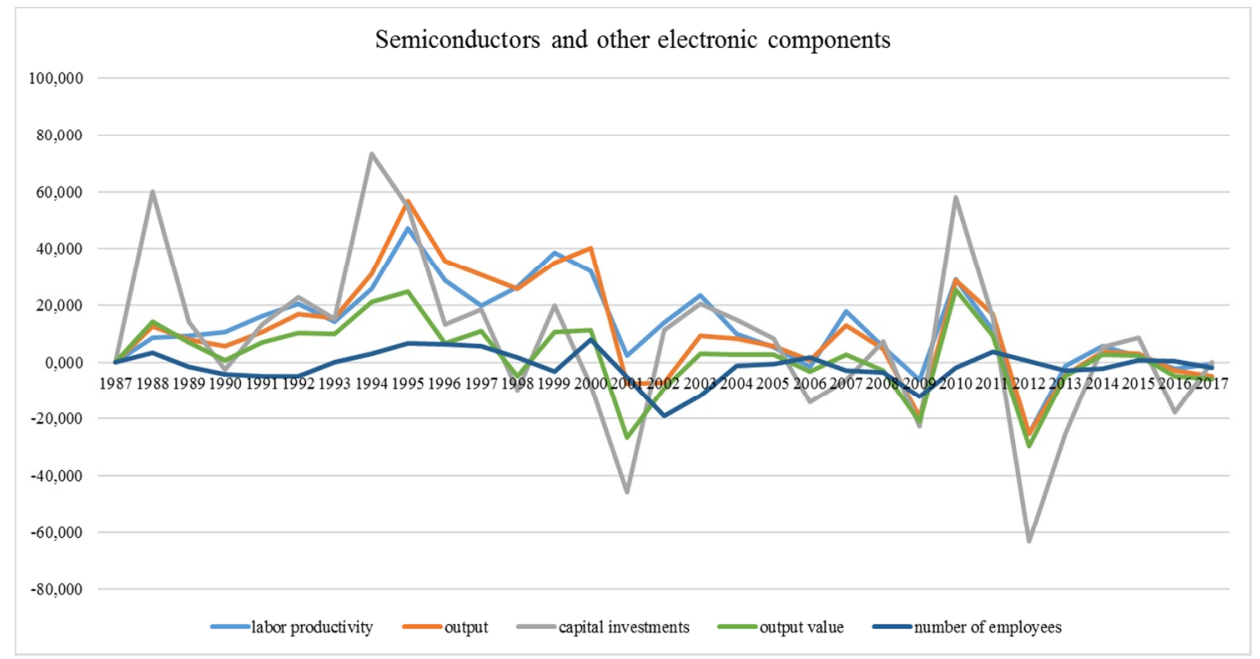

Fig. 4. Growth in semiconductor manufacture [4] 


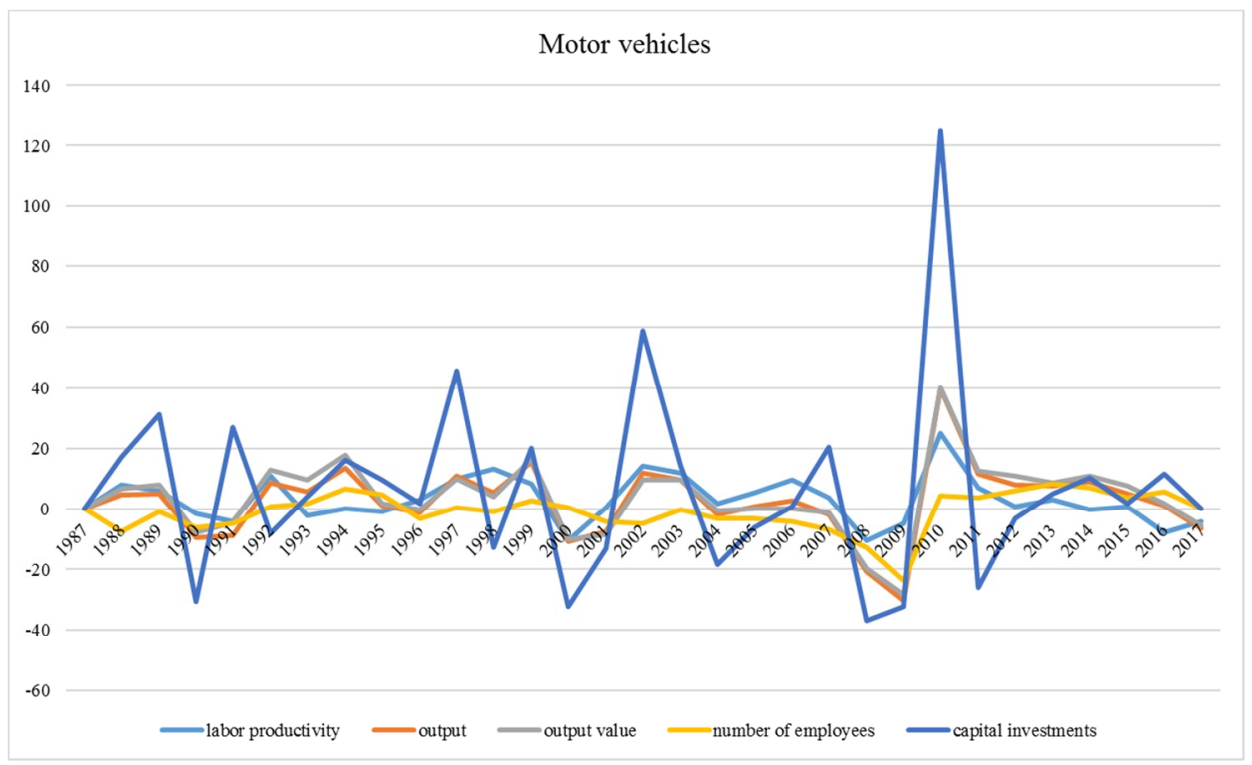

Fig. 5. Growth in motor vehicle manufacture [4]

A sample of industries is according with the structure of American exports. It means competition ability of American exports has fallen because of reducing of labor productivity and decreasing of employment level. It proves a hypothesis about negative affluence of technic innovations to labor productivity.

For comparability and relevance of data now we take a look to services sector role in American economy (Fig 6).

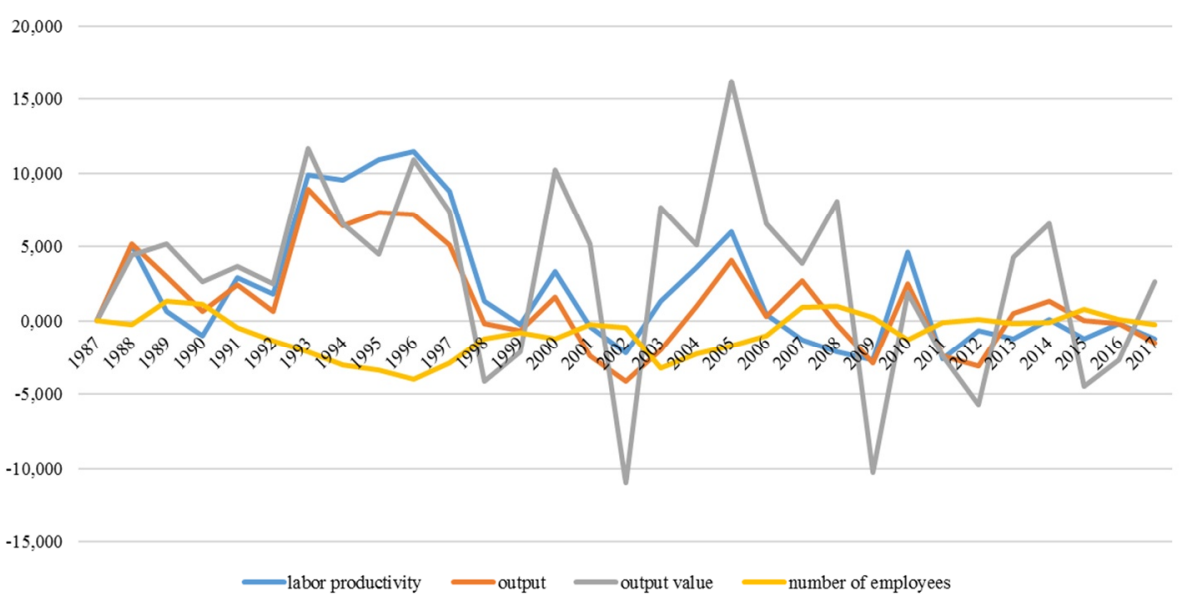

Fig. 6. Growth in utilities [4]

The figure illustrates an addiction between productivity, output and inflation growth and confirms our conclusions about labor productivity. But we should come back to fictive capital and its relation with technologies in different industries.

All of industries considered here are described with stagnation of all the indicators after their rises. Besides, all of them are corresponded with American financial markets dynamics. It seems obviously a relation of these indicators with a level of capacity 
utilization. When it's a boom on financials the fund producing has reached with much more high technical characteristics. But when financial capital changes the direction of flows, it meant technics wasn't paid-off with the existing price scale (Fig.7)

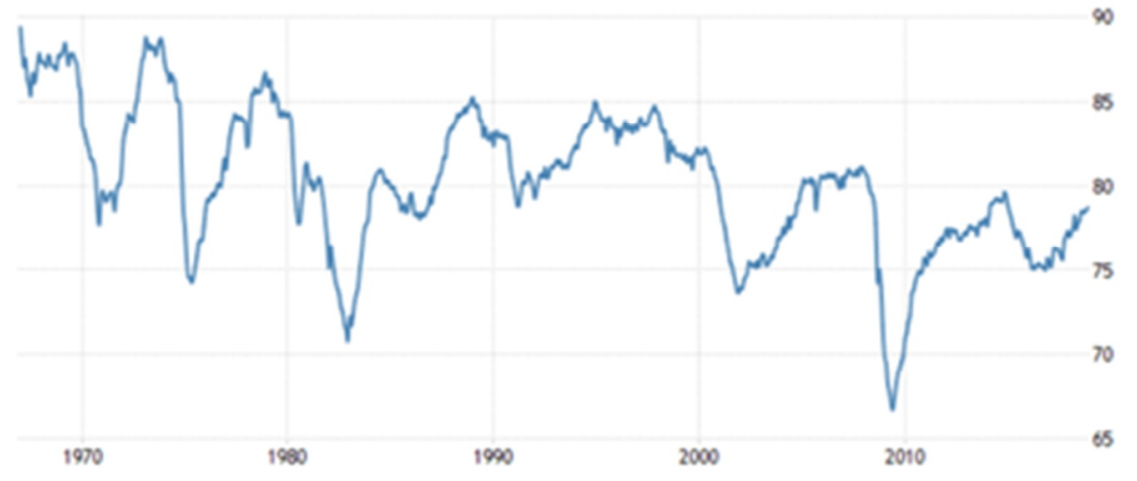

Fig. 7. Capacity utilization in the US [5]

That trend is the last piece of the puzzle in American non-efficient economics, which is covered all over the world by financial capital. Moreover the dynamics of real output in manufacturing industry of the US confirms mistaken decisions about the capital distribution (Fig.8)

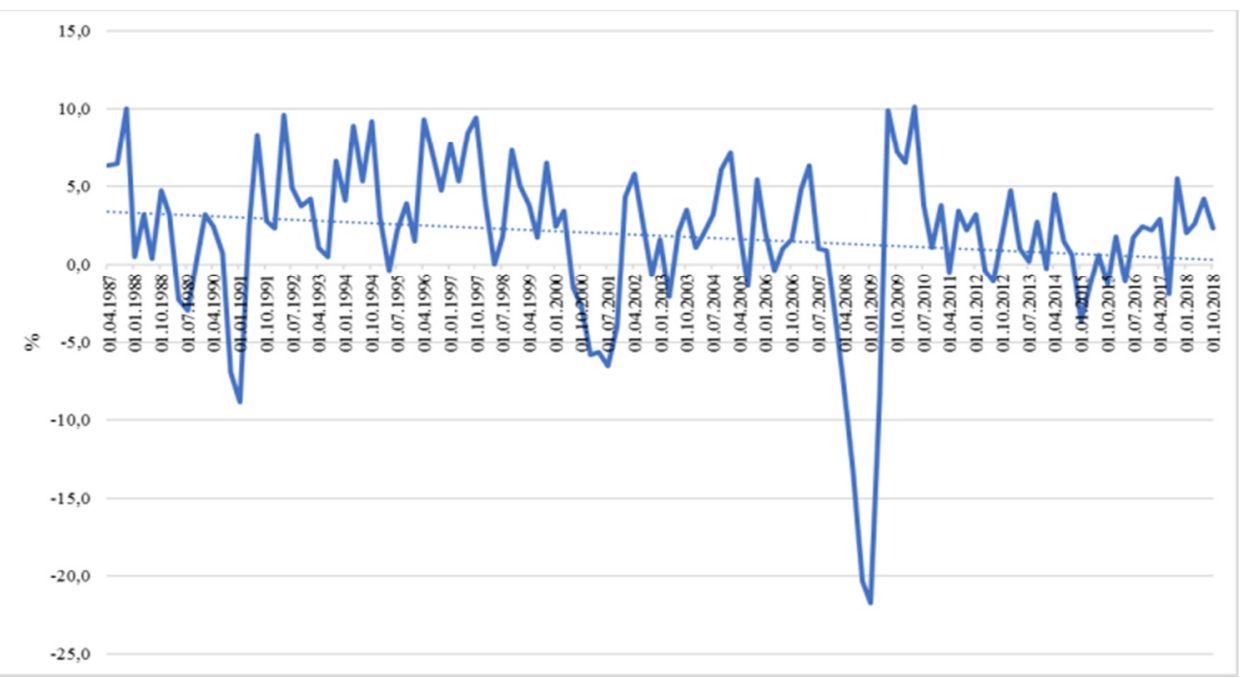

Fig. 8. Real output in the US [6]

So fictive capital gives wrong signals to business by expanding of technical, but not technological innovations. Reducing of labor productivity arrives to liquidity crises when capital costs were lost value and became not returned.

Such problems in a single country shouldn't cause concern. But now we are talking about the issuer of reserve currency. The risk is all other country should pay for the American reducing of productivity. Once more threat is copying of aggressive finance models with huge borrows by another countries, which are responsible for the global growth. Omnivorous of dollar-nominated fictive capital is incredible. The economics of all countries are filling up with dollar-denominated claims because of capital cost increasing. At the same time dollar assets as account entries could become unavailable in one second.

Actually a lot of information is devoted to printing press of FED and its global harmful 
abilities. But dynamics of coin and notes circulation is not comparable with one-day dollar turnover on Forex market only (Fig.10).

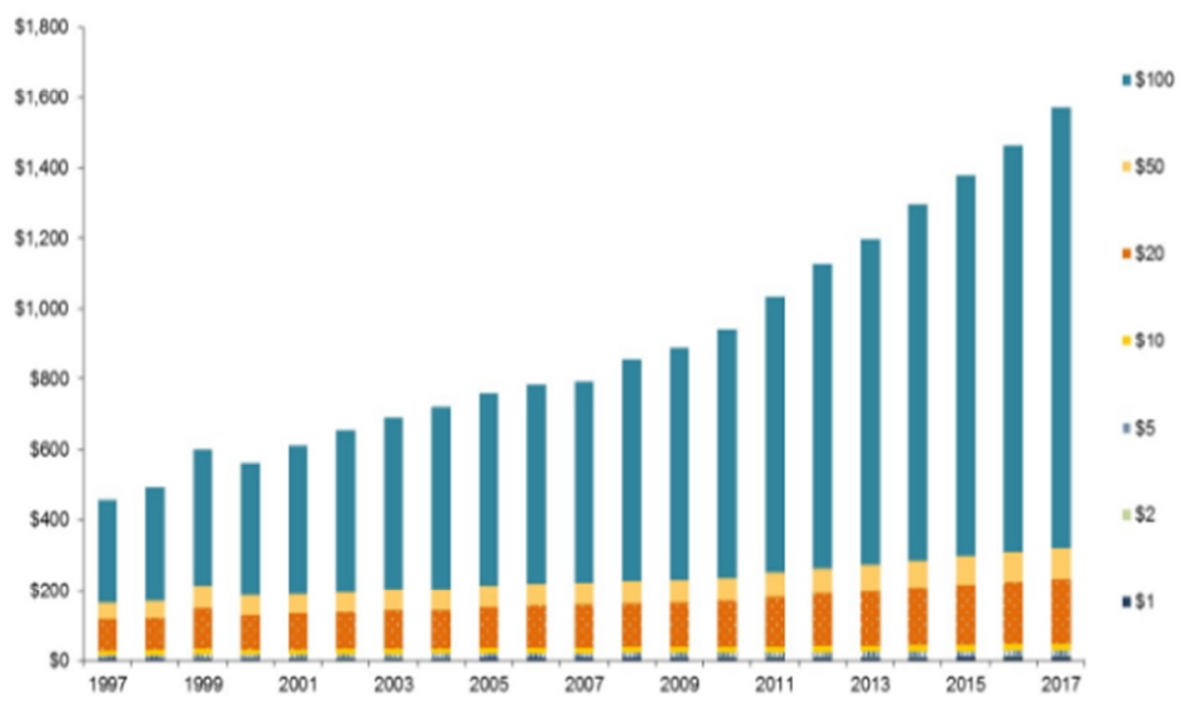

Fig. 9. Monetary circulation in the US [7]

There is some more statistics:

1. International reserves denominated in dollars are 6300 billion (as of the beginning of 2018).

2. Outstanding of dollar liabilities is 10800 billion.

3. Debt secures denominated in dollars are 6280 billion.

4. International credit in dollars is 4300 billion.

5. Total debt of the US is 73000 billion.

6. Derivative market is about 1.2 quadrillion. [8]

At the same time coins and note circulation of dollars is 1531 billion, which is not enough for all dollar transactions. The M2 aggregate includes also deposits, REPO and liquid bonds. For now it is 14500 billion and it isn't enough for cash flows maintenance.

There is a description of monetary imbalance on the book of M. Rothbard named "The Case against the Fed". The reason is FED paid for the assets purchasing by the check endorsed to itself but not by notes issue. Using of checks allows increasing money circulation more than 10 times. So global dollar claims are just electronic account entries and it could become useless for all payments and debt acquaintance [9-12].

\section{Conclusions}

Virtual character of currency is important in terms of performance analysis. Decreasing of labour productivity and stagnation on technologies spreads all over the world by the dollar channel. Needs of transnational companies in dollar space are attempts for redistribution of responsibility. Besides transnational companies redistribute costs to other countries and appropriate an added value. The fictive capital is very useful for this goal achievement. In first banks create deposits in other countries by account entries. Those deposits create loans all over the world. Increasing of credits induces the trade and requires of capital costs and infrastructure investments growth. All these reasons lead to acceleration of fictive capital turnover. Output of these investments and capital costs redistributes to the turnover of 
transnational corporations. Demand falling leads capital losses in all countries posted value producing. But these countries still own production facilities, infrastructure, and vacancies, burdened with dollar loans. And these countries will go to the American financial markets again to get new fictive capital and new account entries.

It's pertinent to remember a default prediction models like Merton's model or logistical model of Russian professor Smirnov. Its item is comparing value of resources and debt estimate in market prices. When a company is insolvent the debt is higher than capitalization or resources cost. Additional debt or debt refinancing is much more expensive for insolvent company, especially if debt is denominated in foreign currency. It means devaluation risk.

During the crisis in 2000-2001 American economy has known risks of cost increase. Those costs would never be returned without inflation or fictive capital. Increasing costs in own economy means necessity of money issue to avoid acute social conflicts. It means undisguised inflation.

That's why the US shift the costs of technical development without technological component to another countries. Dollar basis is necessary element of that politics. It is modern version of initial capital accumulation by transnational corporations. And this version is the key to understanding global expansion of virtual dollar accounts.

\section{References}

1. J. M. Keynes The Yale Review, 22(4) (2019)

2. N.A. Lebedev, A.G. Paptsov, et al. Digital Spaces Magazine. 38 (57), pp. 68-73 (2017).

3. M. Brill, B. Chansky, and J. Kim, Monthly Labor Review (2018)

4. Labor Productivity and Costs (Access date 15/02/2020) URL: https://www.bls.gov/lpc/tables.htm

5. United States Capacity Utilization. (Access date: 18.02.2020) URL: tradingeconomics.com/united-states/capacity-utilization

6. The Observatory of Economic Complexity. (Access date: 18.02.2020) URL: atlas.media.mit.edu/en/profile/country/usa/

7. Board of governors of the Federal reserve system. (Access date: 18.02.2020) URL: www.federalreserve.gov/paymentsystems/coin_data.htm

8. The international role of euro. Statistical annex. (2018)

9. M. Rothbard. Mises Review. 1(1) (1995)

10. P. Aghion, P.A. Howitt. Econometrica, 60(2), 323-351(1992)

11. V.I. Blishchenko, V.G. Egorov, et al. The Social Sciences, 11, 5347-5359 (2016)

12. L. Pushkareva, M. Pushkarev, E3S Web of Conferences 135, 04070 (2019). doi:10.1051/e3sconf/201913504070 